DOI: 10.14451/1.169.41

\title{
ИССЛЕДОВАНИЕ ОРГАНИЗАЦИОННОГО ПОТЕНЦИАЛА ПРОМЫШЛЕННОГО ПРЕДПРИЯТИЯ, КАК ОСНОВНОЙ ЭЛЕМЕНТ ПРОИЗВОДСТВЕННОГО МЕНЕДЖМЕНТА
}

\author{
(c) 2018 Галачиева Светлана Владимировна \\ доктор экономических наук, профессор кафедры экономики и управления \\ Северо-Кавказский горно-металлургический институт (ГТУ) \\ 362021, г. Владикавказ, ул. Николаева, д. 44 \\ E-mail: svetagalachieva@list.ru \\ (c) 2018 Акоева Ирина Владимировна \\ кандидат экономических наук, доцент кафедры экономики и управления \\ Северо-Кавказский горно-металлургический институт (ГТУ) \\ 362021, г. Владикавказ, ул. Николаева, д. 44 \\ (c) 2018 Болиева Инга Ахтемировна \\ кандидат экономических наук, доцент кафедры экономики и управления \\ Северо-Кавказский горно-металлургический институт (ГТУ) \\ 362021, г. Владикавказ, ул. Николаева, д. 44 \\ (c) 2018 Каргинова Вера Витальевна \\ кандидат экономических наук, доцент кафедры экономики и управления \\ Северо-Кавказский горно-металлургический институт (ГТУ) \\ 362021, г. Владикавказ, ул. Николаева, д. 44 \\ (c) 2018 Дедегкаева Нина Таймуразовна \\ аспирант \\ Северо-Кавказский горно-металлургический институт (ГТУ) \\ 362021, г. Владикавказ, ул. Николаева, д. 44 \\ (c) 2018 Гугкаев Вячеслав Ханджериеевич \\ аспирант \\ Северо-Кавказский горно-металлургический институт (ГТУ) \\ 362021, г. Владикавказ, ул. Николаева, д. 44
}

В современных условиях научно-технического прогресса и изменения динамики внешней среды промышленные предприятия вынуждены трансформироваться в более сложные системы, в связи с этим появляется необходимость новых методов обеспечения эффективного менеджмента их развития.

Ключевые слова: производственный менеджент, потенциал, промышленные предприятия, бизнес-план, Метод SADT.

В мировой экономической науке такой инструмент менеджмента, как бизнес-план, уже давно считается устаревшим. Его главный недостаток - невозможность описания на модельном уровне потенциала продвижения продукции на рынке, уровня дальнейшего совершенствования технологии и техники, гибкости структуры организации. Бизнес-план позволяет в виде модели описать лишь финансовые потоки предприятия. Наиболее эффективным его применением мы считаем использование как инструмент привле- чения инвестиций [1].

В настоящее время менеджмент в основном заключается в управлении процессами, а не только людьми, и чтобы ими управлять, следует эти процессы определить, описать и структурировать. В результате появляется цепь взаимосвязанных параллельных и последовательных бизнес-процессов, что, безусловно, существенно осложняет управление ими. Новейшие технологии дают возможность создавать модели всех составляющих менеджмента и для настоящего 
времени, и для будущего, при этом они взаимосвязаны, и изменения в одной модели автоматически вызывают соответствующие изменения в других.

Современные компьютерные технологии повышают качество и скорость обработки информации и управления ею, однако управлять сложными, неопределенными экономическими процессами на основе программирования в принципе невозможно. Достаточно достоверно можно смоделировать статистический или детерминированный процессы, в которых есть неопределённость, но там она подчиняется известным количественным закономерностям. Неопределённость в экономике более высокого порядка, и может быть связана как с ошибками или сознательным искажением участниками процесса управления передаваемой информации, так и с тем, что количественно выражать экономические категории намного сложнее, чем категории технические.

Ещё одной объективной причиной сложности формализации творческих процессов является множественность критериев принятия решения (множественность целевых функций) [3]. Например, использование на предприятии в полном объёме резервов увеличения прибыли в текущем периоде даст возможность улучшить финансовое положение, но при этом увеличится налогооблагаемая база за отчётный период. Если на предприятии сложится кризисное финансовое положение, возможно, не удастся стабилизировать ситуацию вследствие исчерпания резервных возможностей. Таким образом, критерий использования различных факторов или резервов повышения эффективности в разных периодах коррелирует со сложившейся конъюнктурой. Иначе говоря, критериев много, и они порой противоречат друг другу.

Интересы участников процесса менеджмента тоже противоречивы. Естественно, каждый участник этого процесса отстаивает свои интересы, отличающиеся от интересов других участников. Общий результат процесса управления коррелирует с согласованностью интересов всех участников. Если на предприятии хорошо поставлено взаимодействие, в целом оно выигрывает, так как каждый из участников процесса менеджмента в конечном итоге в той или иной мере удовлетворяет свои интересы. В случае, когда такой согласованности нет, одновременно страдают интересы всех его участников.
Таким образом, вышеописанные причины приводят к тому, что вместо формализуемой реакции на колебания экзогенных факторов приходит принятие управленческого решения, т.е. неформальное согласование критериев оптимальности и интересов множества участников процесса управления, которое подразумевает личную ответственность участника за принимаемое решение. Информационные системы в этом случае позволяют своевременно получать информацию, достаточную для соответствующей реакции на событие [2].

Существует три основных этапа бизнес-моделирования: организационное, моделирование бизнес-процессов и количественное моделирование.

На организационном этапе строится организационная модель предприятия, состоящая из функциональной и структурной модели. Первая модель показывает функции, реализуемые предприятием, а вторая - структуры, реализующие эти функции. Структура организационной модели - иерархическая, в соответствии с ней разрабатываются три нормативных документа, которые описывают модель от верхнего уровня до нижнего: 1) положение об организационной структуре, 2) положение о подразделениях, 3) положение о должностных обязанностях.

Организационная модель предприятия может быть представлена в виде программы, которая в западном менеджменте называется orgware («оргвеэ»). Данная технология разработана немецкими экономистами, впервые составившими подробное описание иерархии управления компанией и разработавшими специальные средства, которые поддерживают эту информацию.

Моделирование бизнес-процессов состоит в том, что сам по себе бизнес-процесс - это определенная функция с входными и выходными параметрами, исходя из этого функциональная модель предприятия становится процессной моделью, которая дает возможность выстраивать цепочки связанных между собой бизнес-процессов, имеющих определенные функции, и выявлять их причинно-следственную связь. Эта технология в западном менеджменте называется workflow («вёкфло»), приоритет в разработке ее программного обеспечения и стандартов, описывающих процессы, принадлежит американским экономистам, которые добились лучших показателей в выстраивании горизонталь- 
ных связей [2].

Специфика технологии workflow заключается в том, что в управлении появился фактор времени, позволяющий оценивать управление отдельными операциями бизнес-процессов. Графически их можно представить как плоскую одноуровневую систему со связями между ее компонентами.

Описание бизнес-процесса по технологии workflow проходит в несколько этапов [4]:

1-й этап. Проводится текстовое описание бизнес-процесса без применения специальных моделей или методик описания. Этот способ довольно простой и не нуждается в высокой квалификации исполняющего, однако получаемый результат не позволит создать развернутую систему бизнес-процессов из-за отсутствия стандартных методик описания.

2-й этап. Выстраиваются модели бизнес-процессов. Путем концептуального моделирования определяются цели бизнес-процессов, назначаются исполнители, ответственные за их реализацию. Здесь необходимо учитывать входные, выходные и управляющие данные. На базе концептуальных моделей строятся технологические модели. Технологическое моделирование базируется на использовании технологических карт. Параллельно с процессной моделью, таким же образом структурная модель предприятия превращается в ролевую, которая определяет роль и место в бизнес-процессе каждого работника в зависимости от занимаемой им должности. При совмещении процессной и ролевой моделей появляется модель процессно-ролевая, имеющая неоспоримое преимущество перед организационной моделью: реализацию бизнес-процессов поддерживает современное программное обеспечение, что на данном этапе позволяет автоматизировать управление.

3-й этап. Количественное моделирование. Одно из преимуществ бизнес-процессов - возможность их количественного описания, которое и является сущностью количественного моделирования.

С помощью производственной функции, функции производственного и сетевого планирования можно количественно описать финансовые процессы путем составления бюджетов. По оценкам специалистов, производственные и финансовые процессы можно количественно описать на 90\%, тогда как в маркетинге ему поддается около 10\% всей информации [1].
Одна из причин нежелания инвестировать в развитие систем управления - сложности, с которыми сталкивается предприятие, в нахождении источника финансирования. По нашим наблюдениям, чаще всего руководители промышленных предприятий больше надеются на внешние источники финансирования, не понимая, что обладают внутренними резервами повышения эффективности системы управления, которые дадут возможность осуществить самофинансирование, не привлекая со стороны крупные инвестиции. В этом плане, на наш взгляд, хорошим примером является ситуация с построением организационной модели предприятия, которая позволяет упорядочить функционирование всех систем и подсистем, построить иерархическую структуру их взаимодействия.

Как мы уже отмечали, организационную модель предприятия тоже можно построить с помощью технологии и бизнес-моделирования. $\mathrm{K}$ сожалению, отечественные менеджеры считают этап построения модели пустой тратой средств и времени. На наш взгляд, невозможно принять решение о плановых параметрах модели, не зная ее исходного состояния, кроме того, информация, полученная в результате построения организационной модели, чрезвычайно полезна для построения плановой модели в связи с тем, что существуют определенные закономерности развития сложившейся структуры. К тому же план-фактный анализ, контроль и обратная связь требуют соотнесения показателей состояния модели во времени. Следует разработать плановую модель организационной структуры предприятия: сначала проводится инвентаризация всех видов деятельности и производимых им услуг и продуктов, затем выделяются зоны ответственности на базе полученных ранее данных, при этом обязательно следует опираться на иерархию целей хозяйственной деятельности предприятия. Следующим шагом является закрепление за каждой зоной ответственности конкретного организационного звена, которое должно реализовать цели этой зоны [5].

Последний этап - построение структурной организационной схемы предприятия. Здесь зоны ответственности можно сгруппировать в общую зону по конкретному признаку, к примеру, по виду деятельности, принадлежности или функции управления. За результаты деятельности общей зоны отвечает вышестоящее звено 
управления. Эта технология фактически является организационным конструктором с заданными деталями, изготовленными пользователем, и от их качества зависит общая прочность построенной конструкции.

Последние два этапа процесса конструирования - уже архитектура. В экономической науке все типы структур организации уже хорошо изучены, и аналитикам остается только «примерить» их, основываясь на специфике предприятий, а также позитивных и негативных характеристиках всех типов структур.

В современной науке для конструирования бизнес-процессов существует ряд программных систем: IDEF/Design («Meta Software Corp.»), Bpwin («PLATINUM Technology»), ARIS («IDS Sheer AG»), Rational Rose («Rational Software»), Designer/2000 («Oracle»), Paradigm Plus («CA/ Platinum») и др.

При проектировании программного обеспечения применяется структурный, или функционально-модульный, подход, где чаще всего используются две группы средств, которые описывают функциональную структуру системы и отношения между данными. Этим группам соответствуют определенные виды диаграмм и методов, самыми распространенными среди них являются: диаграммы потоков данных DFD (Data Flow Diagrams); метод структурного анализа и проектирования - SADT (Structured Analysisand Design Technique).

Некоторые экономисты считают, что в нашей стране, в условиях стихийно появляющихся и развивающихся предприятий, следует использовать модели, основанные на потоковых диаграммах. Мы считаем, что при моделировании бизнес-процессов целесообразнее использовать метод SADT, на наш взгляд, пожалуй, это единственная методология, которая позволяет легко представлять управление, обратную связь и механизм исполнения.

Метод SADT - это совокупность правил и процедур, которые предназначены для построения функциональной модели объекта какой-нибудь предметной области. Функциональная модель SADT показывает производимые объектом действия и связи между ними. Элементы метода основываются на графическом представлении блочного моделирования, точности и строгости, на концепции отделения организации от функции, то есть устранении влияния административной структуры на функциональную модель.

Иначе говоря, есть возможность построить модель системы менеджмента, позволяющую функционировать как в настоящем периоде, так и при необходимости быстро внести коррективы в систему управления, соответствующие новым условиям, что даст возможность предприятию поддерживать на должном уровне внутренний потенциал компании в любых условиях внешней среды.

По нашему мнению, бизнес-моделирование - это самый современный и эффективный инструмент менеджмента и выявления резервов эффективного развития самого промышленного предприятия и всех его систем и подсистем.

\section{Библиографический список}

1. Галачиева С.В., Махошева С.А., Амирамова А.М., Хачетлова Е.Р., Попова Т.В., Баранская М.Ф. Организационно-экономические аспекты реструктуризации предприятий легкой промышленности (на материалах Кабардино-Балкарской республики): монография. Владикавказ. 2014. 162 с.

2. Галачиева С.В., Хачетлова Е.Р. Сущность и процесс образования резервов повышения экономической устойчивости в системе хозяйственной деятельности // Устойчивое развитие горных территорий. 2014 № 4 (22). С. 138-144.

3. Тренев Н. Стратегия предприятия: разработка, анализ // Бизнес-Академия. 2014. № 9

4. Хаммер М., Чампи Дж. Реинжиниринг корпорации: Манифест революции в бизнесе / Пер. с англ. Санкт-Петербург. 2007.

5. Хачетлова E.P., Галачиева С.В., Попова Т.В., Баранская М.Ф. Стратегические направления развития промышленного комплекса региона в контексте масштабной модернизации. // Устойчивое развитие горных территорий. 2014 № 3 (21). С. 79-85. 